\title{
Saberes tradicionais, sustentabilidade cultural e caracterização de etnovariedades da mandioca: estudo em uma comunidade no interior do Ceará
}

\author{
Traditional knowledge, cultural sustainability and characterization of cassava ethnovarities: a \\ study in a community in the interior of Ceará
}

Conocimientos tradicionales, sostenibilidad cultural y caracterización de etnovaridades de yuca: un estudio en una comunidad del interior de Ceará

\section{Resumo}

A mandioca Manihot esculenta Crantz se fez presente no Brasil antes mesmo do processo de colonização. Historicamente conhecida como o pão da terra, é cultivada prioritariamente por pequenos agricultores em comunidades tradicionais que adaptam as técnicas de manejo e cultivo da espécie de acordo com as características do solo e do clima local. A mandioca tem características de alto potencial energético e facilidade em adaptações climáticas, assim é amplamente cultivada em todo o território brasileiro. Tendo uma grande variabilidade genética e uma diversidade relevante de etnovariedades, apresenta recursos genéticos importantes para a sua preservação e conservação, podendo ainda ser utilizada em melhoramento genético com ênfase na transferência de genes quantitativos. A importância genética da mandioca está relacionada ao grande número de etnovariedades cultivadas por comunidades tradicionais, empregando o etnoconhecimento construído ao longo de gerações. Assim, buscou-se caracterizar as principais etnovariedades da mandioca de cultivo da comunidade Sítio Santo Antônio, em Beberibe, Ceará, considerando os saberes tradicionais e os descritores agromorfológicos de acordo com a literatura pertinente. Para tanto, foram empregadas técnicas de observação direta, entrevistas com roteiro semiestruturado, aplicação de questionário estruturado, diário de notas de campo e coleta de amostras das etnovariedades para a caracterização conforme os descritores. Foram identificadas cinco etnovariedades, denominadas como sendo mandioca roxa, paulista, rainha do céu, olho verde e fragoza. A etnovariedade olho verde apresenta o caractere de crescimento/altura de melhor desenvolvimento dentre as variedades identificadas; a raiz dessa variedade apresenta desenvolvimento robusto de grande porte, importante para a produção de farinha seca.

Palavras-chave: Saberes tradicionais; Etnovariedades; Descritores agromorfológicos; Sustentabilidade cultural; Mandioca.

\begin{abstract}
Cassava Manihot esculenta Crantz was present in Brazil even before the colonization process, historically known as the bread of the land is cultivated primarily by small farmers in traditional communities who adapt as management and cultivation technicians of the species according to the soil and characteristics. local climate. Cassava has characteristics of high energy potential and ease of climate adaptation, so it is widely cultivated throughout the Brazilian territory, having in turn a great genetic variability, a relevant diversity of ethnovarities, representing important genetic resources for its preservation and conservation. be used in genetic improvement with emphasis on the transfer of quantitative genes, a genetic importance of cassava is related to the large number of ethnovarities cultivated by traditional communities, employing the ethnoknowledge built over generations. Thus, we sought to
\end{abstract}


characterize as main ethnovarities of cassava grown in the community Sítio Santo Antônio in Beberibe, Ceará, considering the traditional knowledge and agromorphological descriptors according to the pertinent literature. For that, observation techniques were used, informing with a semi-structured script, structured questionnaire, field notes diary and collection of ethnovarities for characterization according to descriptors. Five ethnovarities were identified, named as purple cassava, paulista, queen of the sky, green eye and fragoza. The green eye ethnovariety presents the character of growth / height of better development as identified varieties, the root of this variety presents the robust development of large size, important for the production of dry flour.

Keywords: Traditional knowledge; Ethnovelties; Agromorphological descriptors; Cultural sustainability; Manioc.

\section{Resumen}

La Manihot esculenta Crantz estuvo presente en Brasil incluso antes del proceso de colonización. Históricamente conocido como el pan de la tierra, es principalmente cultivado por pequeños agricultores en comunidades tradicionales que adaptan las técnicas de manejo y cultivo de la especie según las características del suelo y el clima local. La yuca tiene características de alto potencial energético y facilidad de adaptación climática, por lo que se cultiva ampliamente en todo el territorio brasileño. Al tener una gran variabilidad genética y una diversidad de etnovaridades relevante, posee importantes recursos genéticos para su preservación y conservación, pudiendo también ser utilizado en mejoramiento genético con énfasis en la transferencia de genes cuantitativos. La importancia genética de la yuca está relacionada con la gran cantidad de etnovaridades cultivadas por las comunidades tradicionales, utilizando el etnoconocimiento construido durante generaciones. Así, se buscó caracterizar las principales etnovaridades de la yuca cultivada en la comunidad Sítio Santo Antônio, en Beberibe, Ceará, considerando conocimientos tradicionales y descriptores agromorfológicos de acuerdo con la literatura pertinente. Para ello se utilizaron técnicas de observación directa, entrevistas con guión semiestructurado, aplicación de un cuestionario estructurado, diario de notas de campo y recolección de muestras de etnovaridades para su caracterización según los descriptores. Se identificaron cinco etnovaridades, nombradas como mandioca morada, paulista, reina del cielo, ojo verde y fragoza. La etnovariedad de ojo verde presenta el carácter de crecimiento / altura con mejor desarrollo entre las variedades identificadas; la raíz de esta variedad presenta un desarrollo robusto de gran tamaño, importante para la producción de harina seca.

Palabras clave: Conocimientos tradicionales; Etnovedades; Descriptores agromorfológicos; Sostenibilidad cultural; Mandioca.

\section{Introdução}

A mandioca historicamente é precursora de alimentos dos mais pobres, fato até hoje defendido pela Organização das Nações Unidas para a Alimentação e a Agricultura. Por características como alto potencial energético e facilidade em adaptações climáticas, foi amplamente cultivada. Em aspectos históricos gerais, a mandioca se fez presente no Brasil antes mesmo do processo de colonização, como alimento dos indígenas, tendo se tornado posteriormente alimento para os navios de tráfico de escravos (Pinto, 2002). Então, durante milênios, sua disseminação abrangeu a América Central, as Antilhas e parte do litoral da América do Sul (Piperno, 2011). Assim, o pão da terra ou mandioca cumpriu papel relevante na colonização, substituindo o trigo, tradicional alimento dos portugueses colonizadores, estando fortemente presente também na alimentação dos escravos (Instituto Americano de Culinária, 2011).

A atividade de cultivo da mandioca ganhou então extenso cultivo em comunidades tradicionais, passando a se relacionar infimamente com o etnoconhecimento construído pelas famílias que a cultivam; a técnica da agricultura tradicional herdada do período de pré-colonização até hoje é a base para o cultivo da mandioca. Os indígenas, como já mencionados, são os principais autores dessas técnicas que são transmitidas às populações geralmente de baixa renda ao longo de gerações. Essas técnicas foram adaptadas conforme os ecossistemas de cada região (Faraldo et al., 2000).

Existem dezenas de etnovariedades utilizadas por agricultores e povos indígenas. Essa ampliação de disseminação de variabilidade ocorre segundo diferentes aspectos, seja por condições socioculturais e ecossistêmicas e/ou fatores econômicos. O papel das populações tradicionais nesse processo é fundamental, sendo o etnoconhecimento utilizado na conservação dessa diversidade genética. Contudo, a adoção de modelos que não contemplam a diversidade causa o efeito de erosão das etnovariedades; além disso, discutem-se os valores intelectuais culturais no cultivo dessas etnovariedades que representam a identidade dos pequenos agricultores e indígenas (Siviero \& Haverroth, 2013). 
Desse modo, faz-se necessária a pesquisa para a divulgação científica do etnoconhecimento desenvolvido pelas comunidades e povos tradicionais, bem como a discussão sobre as relações de conhecimento científico que se entrelaçam ao conhecimento local das comunidades, a fim de auxiliar na melhoria de suas práticas, preservando sua cultura local e divulgando as práticas e técnicas laborais utilizadas.

É pertinente ressaltar que a importância genética da mandioca está em sua extensa variabilidade, relacionada ao grande número de etnovariedades cultivadas por comunidades tradicionais, empregando o etnoconhecimento construído ao longo de gerações (Brasil, 2017). Nessa esteira de realidade, na comunidade de Sítio Santo Antônio, localizada no município de Beberibe, Ceará, o cultivo da mandioca se caracteriza como umas das principais atividades laborais das famílias que compõem a comunidade tradicional de agricultores, carregando a identidade cultural da comunidade, que desenvolve técnicas próprias de cultivo e manejo do solo para o plantio de mandioca e produção da farinha seca e demais subprodutos.

Questiona-se, assim, quais as principais etnovariedades cultivadas pelas comunidades tradicionais da localidade Sítio Santo Antônio e como são caraterizadas, considerando o etnoconhecimento e os descritores agromorfológicos. Configura-se o objetivo da pesquisa como sendo caracterizar as principais etnovariedades da mandioca de cultivo local conforme os saberes tradicionais e os descritores agromorfológicos, de acordo com a literatura pertinente.

Por fim, reforça-se a importância de discutir o etnoconhecimento, permitindo aprimorar técnicas, inter-relacioná-las, registrar, divulgar e construir suporte acadêmico científico para políticas públicas efetivas na valorização desse conhecimento, considerando seu forte impacto ao meio ambiente e aos sistemas socioculturais.

\section{Etnoconhecimento e Etnovariedades da Mandioca}

O etnoconhecimento é discutido nas mais variadas áreas de estudo, seja no âmbito das suas inter-relações com a produção de conhecimento científico e/ou sua aplicação nas diferentes realidades sociais. Contudo, um fato é que o etnoconhecimento está relacionado intimamente com a transmissão de informação pela oralidade entre gerações; essa comunicação é carregada de termos e expressões que caracterizam diferentes aspectos de um grupo social, sua organização, hábitos, identidade e até mesmo localização geográfica, transparecendo sua relação com os ambientes em que vivem, considerando flora e fauna (Franca \& Silveira, 2015).

Nesse viés, o Brasil é um país rico em diversidade cultural e recursos naturais, inclusive essa é uma construção ao longo de anos, aspecto advindo da diversidade de etnias e saberes. Assim, o etnoconhecimento torna-se parte dessa diversidade cultural brasileira, de saberes construídos e transmitidos por gerações, ocorrendo em comunidade tradicionais, sendo apreendidos no cotidiano e em suas interações com os fenômenos naturais. Esse etnoconhecimento é fundamental para a identidade dessas comunidades tradicionais (Nascimento, 2013). Utilizados pelos povos tradicionais para gerenciar os recursos naturais e gerar suas cadeias produtivas, envolvendo as práticas de cultivo, manejo e atividades extrativistas, possibilitam uma relação de equilíbrio entre homem e natureza.

A mandioca é disseminada em todo o território brasileiro, tendo uma grande variabilidade genética. Em uma única área de plantio, é possível identificar uma diversidade relevante de etnovariedades, apresentando, assim, recursos genéticos importantes para preservação e conservação de material, podendo ser utilizado em melhoramento genético com ênfase na transferência de genes quantitativos. O gênero Manihot conglomera cerca de 100 espécies, contudo a única cultivada para comercialização é a Manihot esculenta Crantz. A mandioca é uma espécie cultivada há muito tempo (5.000-7.000 anos antes de Cristo). Sua ampla diversidade genética é resultado da facilidade de polinização cruzada, da sua alta heterozigozidade e da deiscência abrupta dos frutos. Grande parte dessas variedades nativas passou por seleção naturalmente, em que as populações tradicionais exercem potencialmente essa função (Tomich et al., 2008). 


\section{Etnovariedades de Mandioca e a Sustentabilidade Cultural por Comunidades Tradicionais}

Na perspectiva de realidade atual, não apenas no Brasil, mas no mundo, vive-se uma intensa degradação, dada a uma economia potencialmente concentrada em atividades agropecuárias, em uma versão contemporânea e versátil de geração de produtos e/ou serviços, agregada à emergencial necessidade de consumo da população. O resultado desse movimento é a interferência desenfreada nos ecossistemas ambientes naturais e sua funcionalidade; essa interferência alcança também os sistemas culturais (Pinto et al., 2018). Nessa perspectiva, discute-se a importância de conservar e preservar a variabilidade genética da mandioca, bem como as práticas culturais e laborais das populações tradicionais e o seu relevante papel na cultura da mandioca.

A exploração de recursos naturais é crescente e emergencial na atual configuração de globalização, isso ocorre por meio das diversas tecnologias, sendo, porém, importante salientar que os sistemas socioecológicos em sua configuração não conseguem acompanhar essa dinâmica de desenvolvimento (Kolosz et al., 2018). A defesa pela sustentabilidade e preservação de recursos naturais tem ligação direta com a saúde e bem-estar dos seres humanos. Entre tantos impactos de degradação, o solo, por exemplo, tem sofrido forte devastação. A necessidade de produção, que é emergencial, com a crescente demanda mundial, configura um aumento de $60 \%$ na produção global de alimentos e serviços ecossistêmicos associados até 2050 (Rojas et al., 2016).

Em sistemas socioecológicos, consideram-se no processo de desenvolvimento e geração de produtos e subprodutos ou serviços não apenas os recursos naturais, como clima, solo e ecossistema, mas também a influência das ações antrópicas, reconhecendo que a utilização dos recursos naturais envolve sistemas econômicos e, assim, valores sociais, políticas públicas e até mesmo o direito de uso (Buschbacher, 2014). A sociedade quer produtos sustentáveis, a exemplo dos biocombustíveis, havendo uma ínfima relação dos segmentos da sustentabilidade, economia, meio ambiente, sociedade e cultura (Dale, 2016).

Para tanto, além das questões culturais da modernidade, que tem cada vez mais enraizado o utilitarismo nas novas gerações e a necessidade de produção em grandes escalas pelo aumento da população, existem muitas outras questões que pautaram este estudo, a exemplo de um painel organizado pela Elsevier e pela SciDev.Net reunindo pesquisadores, educadores e formuladores de políticas para discutir o desenvolvimento sustentável. Nessa discussão, compreendeu-se que a ciência da sustentabilidade, com a necessidade de desenvolvimento vislumbrada na sociedade atual, tornou-se, portanto, o principal aporte para os mecanismos de promoção do desenvolvimento sustentável, assim as pesquisas têm impulsionado esse desenvolvimento. Mas esse desenvolvimento sustentável pela ciência da sustentabilidade chega em $76 \%$ de pesquisas em países desenvolvidos e apenas em $2 \%$ para os países de baixa renda (Elsevier, 2015). Nessa perspectiva, a discussão em torno de sistemas que promovam a sustentabilidade e/ou o desenvolvimento sustentável, respeitando os sistemas socioculturais que incorporam desde os fatores econômicos, políticos, sociais e culturais, torna-se fundamental.

Nessa esteira, a relação das comunidades tradicionais com os recursos naturais é a demonstração de uma relação entre diversidade, biologia e diversidade sociocultural, em que o manejo dos recursos naturais possui uma interação dos valores, regras e conhecimentos das comunidades. São esses conjuntos de segmentos que ditarão o uso dos recursos e as práticas exercidas pelas comunidades que respeitam os espaços produtivos, desse modo resultam em uma interação de equilíbrio entre homem e natureza (Brasil, 2009).

O Decreto $n^{\circ}$ 6.040, de 7 de fevereiro de 2007, instituiu a Política Nacional de Desenvolvimento Sustentável dos Povos e Comunidades Tradicionais, neste sentido o decreto trata comunidades e povos tradicionais como sendo grupos de indivíduos que possuem uma forma própria de organização social, utilizando recursos naturais para a economia própria, além de tradições ancestrais, transmitindo às gerações, por meio da tradição, os conhecimentos adquiridos, ocupando espaços e utilizando esse território seguindo os princípios ancestrais. Estão configurados como povos e/ou comunidades tradicionais, 
indígenas, quilombolas, pescadores, artesãs, entre outros (Brasil, 2007). Nessa perspectiva, a crescente demanda global a favor da preservação da natureza, além de diferentes perspectivas preservacionistas das correntes ambientalistas da atualidade, considera as comunidades tradicionais protagonistas na preservação dos ambientes nos quais estão inseridas (Pereira \& Diegues, 2010).

Com seus saberes tradicionais e organização social e econômica diferenciada das comunidades urbanas que interagem em um contexto industrializado, essas comunidades tradicionais possuem amplo conhecimento sobre a natureza e o espaço onde exercem suas atividades de subsistência e extrativismo, caracterizando seu modus vivendi, compreendendo, assim, sua identidade. Esse pertencimento à natureza permite que sua economia e ações sejam vivenciadas de maneira dependente com o meio ambiente; utilizam-se, portanto, tecnologias simples para as atividades, causando pouco impacto destrutivo à natureza. $\mathrm{O}$ desenvolvimento de suas práticas geralmente é por meio artesanal, tornando-se a unidade familiar importante para a reprodução cultural e econômica; essas comunidades têm consciência da relação de dependência com a natureza e os recursos oferecidos por ela, assim possuem um modus operandi que se preocupa com a conservação do meio ambiente (Macedo, 2015).

Mesmo com a compreensão da relevante participação das comunidades tradicionais para a conservação do meio ambiente, como agentes fundamentais em produção de uma relação de equilíbrio entre homem e natureza, e dos dispositivos legais prevendo uma política nacional de desenvolvimento sustentável para essas comunidades e povos tradicionais, a realidade se afasta cada vez mais do reconhecimento e valorização desses saberes tradicionais e práticas culturais (Macedo, 2015). É necessário, portanto, que os cenários acadêmicos, políticos e de discussão cultural sejam espaços para a promoção de ações efetivas na preservação, valorização e conservação de comunidades tradicionais que gerenciam a sociobiodiversidade em cadeias sustentáveis de produção de serviços e produtos.

Nessa relação entre recursos naturais e sistemas socioculturais das comunidades tradicionais, que resultam em produtos, subprodutos e serviços, surge o conceito da sociobiodiversidade, segundo o Plano Nacional de Promoção das Cadeias de Produtos da Sociobiodiversidade, elaborado em 2007 pelo Ministério do Meio Ambiente, a fim de gerenciar ações integradas de fortalecimento dos produtos da sociobiodiversidade, contemplando em suas diretrizes o aproveitamento do manejo sustentável em áreas naturais por comunidades tradicionais, com o objetivo de efetivar suas cadeias produtivas e incorporá-las ao mercado (Brasil, 2009).

Nessa expressividade de uma inter-relação equilibrada entre diversidade biológica e diversidade de sistemas socioculturais desenvolvida por comunidades tradicionais, faz-se necessária uma ampla discussão crítica e reflexiva do reconhecimento e valorização dos saberes transmitidos e práticas dessas comunidades, a fim de perpetuar práticas sustentáveis e valoração do etnoconhecimento.

\section{Procedimentos Metodológicos de Coleta/Geração de Dados e Resultados}

No que diz respeito à metodologia, a pesquisa foi realizada no âmbito empírico, com a principal fonte de informações em campo utilizando observações e entrevistas, embasando-se no referencial teórico pertinente para a metodologia. Como método, recorreu-se ao modelo indutivo e fenomenológico, sendo esta uma pesquisa exploratório-descritiva, de abordagem mista (quanti-quali). Quanto às técnicas de coleta de dados, foi empregada a observação direta do contexto dos sujeitos a fim de realizar a descrição do locus da pesquisa, bem como entrevistas com roteiro semiestruturado, em que os participantes foram identificados como A1, A2 e assim consecutivamente, aplicação de questionário estruturado e diário de notas de campo para a coleta de dados quantitativos. Na análise agromorfológica, foi realizada a coleta de amostras das etnovariedades para a caracterização conforme os descritores, de acordo com Fukuda e Guevara (1998). No tocante à técnica de análise de dados, foram utilizadas a análise do discurso narrativo para os dados qualitativos e a estatística descritiva para o levantamento 
quantitativo (Chizzotti, 2011; Gil, 2010; Popper, 2013; Severino, 2013).

A pesquisa teve como cenário a comunidade de Sítio Santo Antônio, que se localiza no estado do Ceará, no município de Beberibe, mais especificamente no distrito de Sucatinga. A região tem raízes históricas indígenas, muito embora os relatos sejam documentados em poucas obras de literatura, como o livro de Soraia Colaço intitulado Beberibe: a história de um povo diversidade e identidade cultural. Beberibe é uma cidade predominantemente costeira, de clima tropical, mas possui uma abrangência territorial que se estende aos ares do semiárido do sertão, com média de 53.421 habitantes e área territorial de $1.623,878 \mathrm{~km}^{2}$, projetando uma densidade demográfica de 30,37 habitantes por $\mathrm{km}^{2}$. No cenário de vegetação, identificam-se a caatinga, os tabuleiros costeiros, o cerrado e o mangue próximo à zona litorânea. Tais características estão bem distribuídas em sete distritos, dentre estes Sucatinga, distrito da comunidade locus desta pesquisa (Brasil, 2017).

Figura 1 - Localização do distrito de Sucatinga, locus da pesquisa.

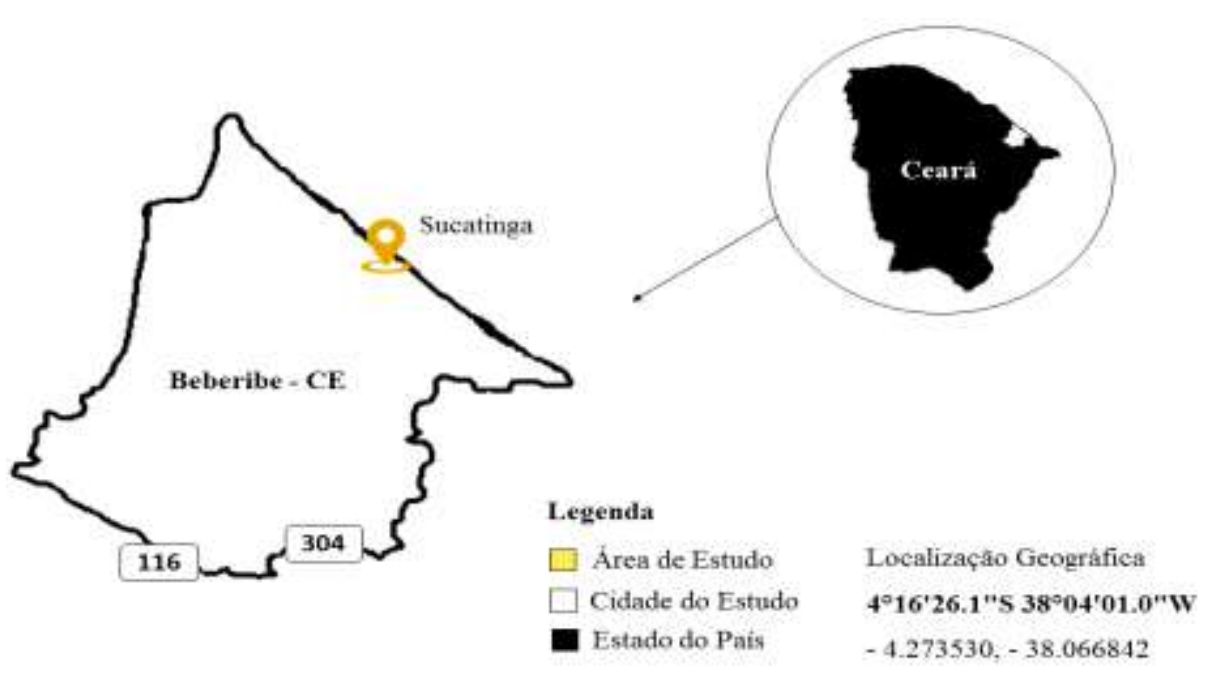

Fonte: Autores (2019).

Os trabalhos de coleta desta pesquisa tiveram início em dezembro de 2018, quando ocorreram as primeiras visitas à comunidade locus. A comunidade tem vegetação de caatinga, possui atualmente 566 habitantes, com área de unidade territorial ainda desconhecida em registros legais do município. A cultura da mandioca é integrada à identidade local e suas práticas laborais de subsistência; essa cultura está presente desde apropriação da área. A história local é contada a partir das raízes de suas gerações, construindo registros vivos socioculturais sobre seus conhecimentos, que são repassados pela oralidade e práticas de manejo e cultivo do solo no plantio da mandioca.

Os pequenos agricultores que compõem comunidades como essas são os protagonistas do cultivo da mandioca Manihot esculenta no Brasil, construindo, a partir dessa prática, uma rede de saberes com identidades e singularidades de cada região. De modo geral, a cultura da mandioca é a principal renda familiar desses agricultores, constituindo uma média de renda, segundo o censo do Instituto Brasileiro de Geografia e Estatística (IBGE) de 2010 de R \$ 197,92 por indivíduo (Brasil, 2017). No cenário de pesquisa, identificam-se três casas de farinha ativas e outras duas desativadas; estas são espaços onde acontece o processamento das raízes da mandioca.

Por fim, no que diz respeito aos critérios de não inclusão, foram excluídos participantes da entrevista com tempo menor do que 30 anos no exercício da agricultura e/ou atividade em casas de farinhas. Para os aspectos éticos, seguiram-se as conformidades da Resolução nº 510/2016 do Conselho Nacional de Saúde, solicitando-se aos participantes da pesquisa que tomassem conhecimento do Termo de Consentimento Livre e Esclarecido. 


\section{Resultados e Discussão}

Os caracteres agromorfológicos denominados de descritores, tendo por base a metodologia descrita por Fukuda e Guevara (1998), foram os seguintes: hábito de crescimento, altura/crescimento, caule: coloração externa, coloração interna, proeminência das gemas, folha: número de lóbulos, cor do pecíolo, raiz: cor da película externa, cor do córtex, forma e tamanho.

$\mathrm{Na}$ óptica agronômica, a variedade de espécies auxilia no controle de pragas, além de ser possível selecionar naturalmente as espécies mais resistentes e de alta qualidade na produção. É o caso da mandioca, tradicionalmente cultivada em diferentes regiões por pequenos agricultores de comunidades tradicionais, originando uma variedade de espécies oriundas da seleção dos próprios produtores (Stefanello et al., 2012). A caracterização agromorfológica das etnovariedades possibilita a diferenciação fenotípica, diminuindo duplicações e gerando a seleção de material de plantio de alta qualidade, aumentando consequentemente a produção de subprodutos. A seguir, no Quadro 1, há a caracterização agromorfológica de cinco principais etnovariedades identificadas no locus da pesquisa.

Quadro 1 - Principais etnovariedades de mandioca na comunidade de Sítio Santo Antônio e seus respectivos descritores agromorfológicos.

\begin{tabular}{|c|c|c|c|c|c|}
\hline Características & Roxa & Paulista & $\begin{array}{l}\text { Rainha do } \\
\text { céu }\end{array}$ & Olho verde & Fragoza \\
\hline $\begin{array}{c}\text { Hábito de } \\
\text { crescimento }\end{array}$ & Ramificações & Reto & Reto & Curva-se ao solo & Ramificações \\
\hline $\begin{array}{c}\text { Altura/ } \\
\text { crescimento }\end{array}$ & $\begin{array}{c}1 \mathrm{~m} 90 \mathrm{~cm} / \\
11 \text { meses de } \\
\text { cultivo }\end{array}$ & $\begin{array}{c}1 \mathrm{~m} 20 \mathrm{~cm} / \\
11 \text { meses de } \\
\text { cultivo }\end{array}$ & $\begin{array}{c}2 \mathrm{~m} 26 \mathrm{~cm} / \\
11 \text { meses de } \\
\text { cultivo }\end{array}$ & $\begin{array}{c}3 \mathrm{~m} 08 \mathrm{~cm} / \\
11 \text { meses de cultivo }\end{array}$ & $\begin{array}{c}2 \mathrm{~m} 36 \mathrm{~cm} / \\
11 \text { meses de } \\
\text { cultivo }\end{array}$ \\
\hline $\begin{array}{l}\text { Caule: } \\
\text { coloração } \\
\text { externa }\end{array}$ & $\begin{array}{l}\text { Marrom- } \\
\text {-escura }\end{array}$ & $\begin{array}{l}\text { Marrom- } \\
\text {-clara }\end{array}$ & Dourada & Marrom-escura & Marrom-clara \\
\hline $\begin{array}{c}\text { Caule: } \\
\text { coloração } \\
\text { interna } \\
\end{array}$ & Creme & Amarelada & Verde-clara & Amarelada & Verde-clara \\
\hline $\begin{array}{c}\text { Caule: } \\
\text { proeminência } \\
\text { das gemas }\end{array}$ & Alta & Alta & Baixa & Alta & Alta \\
\hline $\begin{array}{l}\text { Folha: } \mathbf{n}^{\circ} \text { de } \\
\text { lóbulos }\end{array}$ & 7 & 7 & 7 & 7 & 7 \\
\hline $\begin{array}{l}\text { Folha: cor do } \\
\text { pecíolo }\end{array}$ & Roxa & Verde & Vermelha & Verde & Verde \\
\hline $\begin{array}{c}\text { Raiz: cor } \\
\text { película externa }\end{array}$ & $\begin{array}{l}\text { Marrom- } \\
\text {-escuro }\end{array}$ & $\begin{array}{l}\text { Marrom- } \\
\text {-clara }\end{array}$ & $\begin{array}{l}\text { Marrom- } \\
\text {-escuro }\end{array}$ & Marrom-escura & $\begin{array}{l}\text { Marrom- } \\
\text { escura }\end{array}$ \\
\hline $\begin{array}{l}\text { Raiz: cor do } \\
\text { córtex }\end{array}$ & Amarela & Arroxeada & Branca & Branca & Branca \\
\hline $\begin{array}{l}\text { Raiz: forma e } \\
\text { tamanho }\end{array}$ & $\begin{array}{l}\text { Rugosa/ } \\
\text { Cônico- } \\
\text {-cilíndrica }\end{array}$ & $\begin{array}{l}\text { Rugosa/ } \\
\text { Cônico- } \\
\text {-cilíndrica }\end{array}$ & $\begin{array}{l}\text { Rugosa/ } \\
\text { Cilíndrica }\end{array}$ & $\begin{array}{l}\text { Rugosa/ } \\
\text { Cônica }\end{array}$ & $\begin{array}{l}\text { Rugosa/ } \\
\text { Cônica }\end{array}$ \\
\hline
\end{tabular}

Fonte: Autores (2019). 
De acordo com os dados apresentados, é possível identificar a duplicidade de algumas características das etnovariedades expostas: quanto ao hábito de crescimento, as etnovariedades de mandioca roxa e fragoza possuem ramificações, enquanto a paulista e a rainha do céu possuem hábito reto; as mandiocas roxas e paulistas são consideradas mansas de acordo com os agricultores participantes da pesquisa, mas se diferenciam em caracteres morfológicos. Já quanto ao caractere altura/crescimento, a rainha do céu e a fragoza se aproximam, com a diferença de 10 centímetros apenas; no que se refere à coloração interna do caule, elas também apresentam duplicidade das características, sendo possível identificar outras duplicidades no Quadro 1 a partir dessas percepções de duplicidade nos caracteres morfológicos e diferenças de classificação nos grupos mansas e bravas.

É possível compreender, portanto, que os agricultores desenvolvem suas técnicas de caracterização e classificação das mandiocas agregando o máximo de informações e observações para a construção do etnoconhecimento. De acordo com os relatos, destacam as espécies bravas e mansas, observando não apenas os aspectos morfológicos, mas também o teor de ácido cianogênico; obviamente que essa percepção não conta com ensaios laboratoriais de verificação do composto, sendo constatada apenas com informações passadas pelas gerações e observações nas práticas laborais, como o forte odor, que, quando inalado durante o processamento das raízes nas casas de farinha, chega a causar amargor no paladar, além do comportamento dos substratos das raízes do tipo brava quando ingeridos in natura por animais, causando-lhes intoxicação.

Partindo do etnoconhecimento sobre as raízes que são classificadas como mansas e bravas, realiza-se o plantio diversificando as etnovariedades, uma vez que as mandiocas mansas também são utilizadas para consumo em mesa, fazendo parte da dieta das famílias. Os agricultores identificam morfologicamente as etnovariedades a partir da observação da coloração do pecíolo e hábito de crescimento. Destacam ainda que a qualidade de produção está relacionada também ao manejo do solo e ao período de desenvolvimento das raízes. Estudos realizados em diversas regiões do Brasil destacam a coerência dos agricultores na diferenciação das etnovariedades. Essa variabilidade genética promovida nas áreas de plantio é realizada a partir de saberes tradicionais, sendo fundamental para a conservação in situ, bem como para estudos de diversidade e evolução da espécie. A narrativa do participante A17 apresenta a forma de seleção feita pelos agricultores, além da identificação das etnovariedades a partir dos saberes tradicionais:

A maniva é doada pelos outros agricultores. Quando um termina a arranca (colheita), passa a maniva para o outro, assim vai passando. Na hora de escolher, a gente escolhe os caules mais grossos e verdes das mandiocas mais fortes; dá para saber qual é mandioca pela cor do caule; as macaxeiras têm a cor mais escura; as melhores de plantar são a rainha do céu, que têm a cor mais clara, e a olho verde, que é mais escura e tem o olho da folha verde.

As variedades de mandioca distribuídas pelo Brasil são oriundas da seleção feita pelos pequenos agricultores. Diferentemente dos investimentos para outras culturas no país, a mandioca não tem material e sistema de produção bem definidos, por isso a Empresa Brasileira de Pesquisa Agropecuária (Embrapa) divulga em uma apostila sobre a cultura da mandioca, práticas de manutenção do solo, melhoramento genético de cultivares da mandioca na região do Pará, processamento de subprodutos, entre outras práticas (Homma, 2014). A dificuldade também está no acesso a essas informações, uma vez que os agricultores de pequeno porte não possuem nível de escolaridade equivalente ao material publicado; diante disso, as políticas públicas devem interagir com esses agricultores e agricultoras a fim de transmitir e captar esse conhecimento, gerando uma homogeneidade dos saberes, mas também os preservando. A seguir, na Figura 1, estão os registros das etnovariedades investigadas no locus de pesquisa. 
Figura 1 - Etnovariedades de mandioca na comunidade de Sítio Santo Antônio, Beberibe.

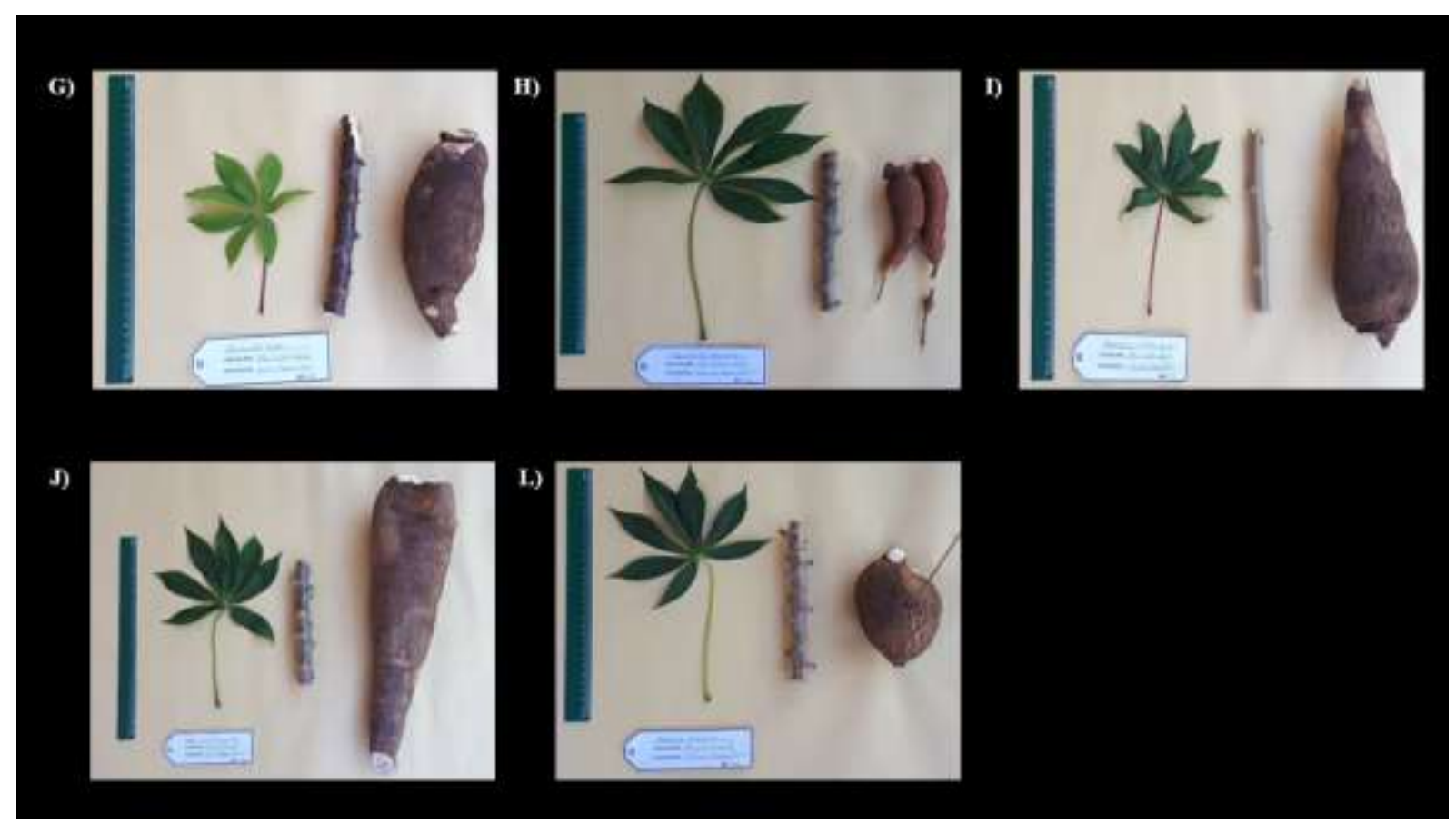

Legenda: G) Folha, caule e raiz da macaxeira roxa; H) Folha, caule e raiz da macaxeira paulista; I) Folha, caule e raiz da mandioca rainha do céu; J) Folha, caule e raiz da mandioca olho verde; L) Folha, caule e raiz da mandioca fragoza.

Fonte: Autores (2019).

A ampliação da variabilidade da Manihot esculenta Crantz é praticada pelos agricultores a partir do etnoconhecimento, sendo fundamental para preservação e conservação da diversidade genética. Essa ampliação ocorre de diversas formas nas várias regiões do país, considerando as questões socioculturais, econômicas e fatores ecológicos. Assim, as comunidades tradicionais têm papel fundamental na conservação da diversidade genética e no enfrentamento de sistemas de cultivo que não visam à diversidade genética, refletindo no efeito de erosão genética das etnovariedades da mandioca (Siviero \& Haverroth, 2013).

No Gráfico 1, observa-se a predominância de pelo menos três etnovariedades nas áreas preservadas para a produção de farinha e subprodutos; a etnovariedade olho verde é predominante em $50 \%$ das áreas investigadas e a rainha do céu, em $30 \%$. 
Gráfico 1 - Predominância de etnovariedades da mandioca nas áreas de plantio da comunidade de Sítio Santo Antônio, Beberibe

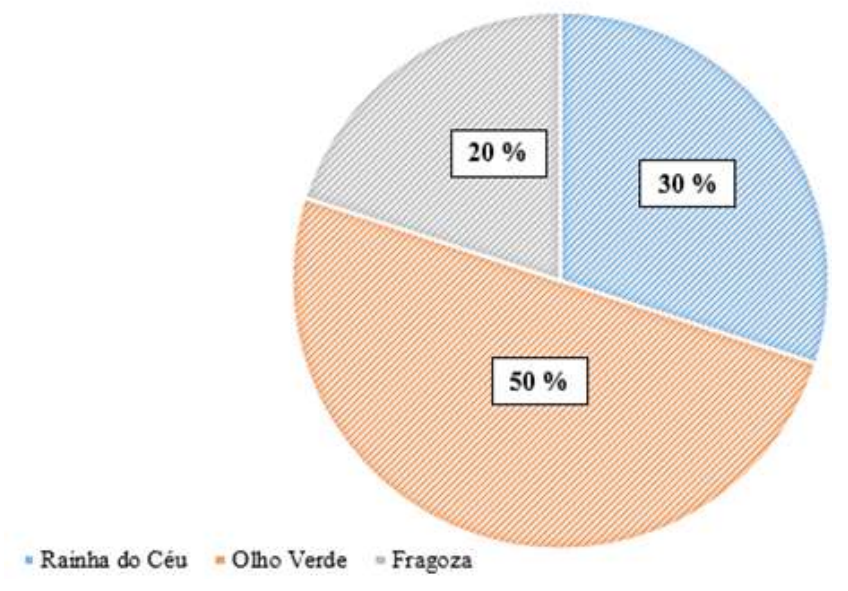

Fonte: Autores (2019).

Apesar da fácil adaptação da mandioca a diversos ambientes, com escassez de água e variação de clima, nutrição, etc., é possível afirmar que um mesmo genótipo não se comporta igualmente em ambientes diferentes (Flores, 2013). Assim, o destaque de predominância das etnovariedades pode variar de acordo com as condições ambientais, como manejo do solo, culturas intercaladas de grãos que auxiliem na fixação de nutrientes, chuva e temperatura do ambiente, o que é possível identificar na narrativa do participante A35, a seguir:

Antigamente se plantava mais a fragoza quando tinha muita chuva e a terra era mais forte, porque a mandioca era boa para fazer a farinha render e também dava para tirar muita goma (fécula). O lucro com a fragoza era bom; as chuvas diminuíram e nós fomos plantando mais a olho verde e misturando com as outras; as macaxeiras a gente não usa para fazer farinha; a gente cozinha.

Um fator importante de destacar é a diferenciação das etnovariedades mansas e bravas, estas destacadas no gráfico 1 para a produção de farinha e subprodutos; tradicionalmente as espécies mansas são consumidas à mesa, conhecidas como macaxeira, as quais concentram baixo teor de ácido cianogênico, menor do que 100mg/kg (Bolhuis, 1954). Isso justifica a predominância das três etnovariedades expressas no gráfico, uma vez que são consideradas bravas pelos agricultores locais. Porém, não é possível afirmar que essas etnovariedades são restritamente bravas, sendo necessário um estudo de testes bioquímicos (Pinto, 2002).

Os saberes tradicionais empregados no cultivo da mandioca expressam a importância das comunidades tradicionais no papel de preservação. Essa relação ínfima com a natureza demonstra a construção de um conhecimento a partir de um modo de vida, e vice-versa. São necessários, portanto, dispositivos legais prevendo uma política nacional que disponha de um desenvolvimento sustentável para essas comunidades e de valorização desses saberes tradicionais e práticas culturais (Macedo, 2015).

Nessa perspectiva da construção de etnoconhecimento com técnicas para a caracterização das etnovariedades que permitem a variabilidade e a seleção de espécies de alta performance agromorfológica, além de práticas culturais sustentáveis, torna-se necessário considerarmos a discussão sobre o cenário das atividades de agricultura, que, junto com a agropecuária, são responsáveis por $65 \%$ da devastação de ambientes naturais no Brasil, segundo o IBGE. Diante disso, as comunidades tradicionais apresentam uma forma de se relacionar com o meio em uma cultura de equilíbrio, observação e manutenção dos 
espaços naturais, que concedem alimento e identidade cultural a esses povos. A implementação de ações governamentais concretas para a valorização dos produtos, serviços e saberes das comunidades tradicionais se faz necessária e emergencial.

\section{Considerações Finais}

Foram identificadas cinco etnovariedades principais de mandioca Manihot esculenta na comunidade locus da pesquisa, caracterizando-se os seguintes descritores agromorfológicos: hábito de crescimento, altura/crescimento, caule: coloração externa, coloração interna, proeminência das gemas, folha: número de lóbulos, cor do pecíolo, raiz: cor da película externa, cor do córtex, forma e tamanho. As mandiocas são classificadas pelos agricultores da comunidade conforme os dados coletados, denominandose como sendo mandioca roxa, paulista, rainha do céu, olho verde e fragoza. Para essa classificação, os agricultores desenvolvem técnicas próprias de caracterização e classificação das mandiocas, agregando o máximo de informações e observações para a construção do etnoconhecimento, característica importante das comunidades e povos tradicionais, que revela sua relação com o meio natural, fortalecendo uma relação de respeito e preservação. Além da caracterização agromorfológica, os agricultores fazem a diferenciação das etnovariedades em mansas e bravas, destinando ao consumo in natura as mansas, denominadas macaxeiras, e as mandiocas bravas são indicadas a um processamento complexo e manufaturado, dividido em diversas etapas para a obtenção de subprodutos. Quanto à predominância de etnovariedades da mandioca nas áreas de plantio, destacam-se a olho verde, a fragoza e a rainha do céu. A etnovariedade olho verde apresenta o caractere de crescimento/altura de melhor desenvolvimento dentre as variedades identificadas; conforme a figura 1, imagem I, a raiz dessa variedade apresenta desenvolvimento robusto de grande porte, importante para a produção de farinha seca.

Nesse ínterim, a partir deste estudo, compreende-se que a caracterização de etnovariedades não apenas contribui com a variabilidade de espécies mais resistentes a pragas e auxilia no controle destas, como também seleciona espécies de boa qualidade para a produção de subprodutos, fortalecendo o cultivo da mandioca pelos pequenos agricultores. Além de evitar a monocultura de espécies, possibilita também a manutenção de culturas sustentáveis, não apenas de práticas com o meio natural, mas também de sustentabilidade do etnoconhecimento local.

A partir deste estudo, foi possível discutir as técnicas de caracterização da comunidade fundamentadas em saberes tradicionais, inter-relacioná-las com conhecimento científico utilizando descritores agromorfológicos, além de refletir sobre o papel das políticas públicas que possibilitem a valorização, a preservação e a manutenção desses conhecimentos construídos a partir da oralidade e das práticas laborais de gerações passadas às gerações presentes.

\section{Referências}

Bolhuis, G. G. (1954). The toxicity of cassava roots. Netherlands Journal of Agricultural Science, 2(3), 176-185.

Brasil. (2007a) Decreto $\mathrm{n}^{\circ}$ 6.040, de 7 de fevereiro de 2007. Institui a Política Nacional de Desenvolvimento Sustentável dos Povos e Comunidades Tradicionais. Diário Oficial [da] República Federativa do Brasil, Poder Executivo, Brasília, DF, 8 fev.

Brasil. (2007b). Povos e Comunidades Tradicionais. MMA.

Brasil. (2009). Plano Nacional de Promoção de Cadeias de Produtos da Sociobiodiversidade. MDS.

Brasil. (2016). Resolução n ${ }^{\circ}$ 510, de 7 de abril de 2016. Dispõe sobre as normas aplicáveis a pesquisas em Ciências Humanas e Sociais cujos procedimentos metodológicos envolvam a utilização de dados diretamente obtidos com os participantes ou de informações identificáveis ou que possam acarretar riscos maiores do que os existentes na vida cotidiana, na forma definida nesta Resolução. Diário Oficial [da] República Federativa do Brasil, Poder Executivo, Brasília, DF, 8 abr.

Buschbacher, R. (2014). A teoria da resiliência e os sistemas socioecológicos: como se preparar para um futuro imprevisível? RCIPEA, 9, 11-24.

Chizzotti, A. (2011). Pesquisa em ciências humanas e sociais (4a ed.). Vozes.

Colaço, S. (2008). Beberibe: a história de um povo - diversidade e identidade cultural. Omni.

Dale, B. E. (2016). Back to the (sustainable) Future! Biofuels, Bioproducts \& Biorefining, 10(1), 5-7. 
Elsevier. (2015). Turning sustainability on its head before UN summit. https://www.elsevier.com/connect/turning-sustainability-on-its-head-before-unsummit\#

Faraldo, M. I. F., Silva, R. M., Ando, A., \& Martins, P. S. (2000). Variabilidade genética de etnovariedades de mandioca em regiões geográficas do Brasil. Scientia Agrícola, 57(3), 499-505.

Flores, M. J. M. (2013). Morfologia e meiose em cultivares e escapees de mandioca (Manihot esculenta Crantz) [Dissertação de Mestrado, Universidade de Brasília].

Franca, A. S. \& Silveira, N. C. (2015). Representação do etnoconhecimento sob a ótica da epistemografia interativa. Anais do XVI Encontro Nacional de Pesquisa em Ciência da Informação. UFPB.

Fukuda, W. M. G. \& Guevara, C. L. (1998). Descritores morfológicos e agronômicos para a caracterização de mandioca (Manihot esculenta Crantz). Emprapa.

Gil, A. (2010). Como elaborar projetos de pesquisa. Atlas.

Homma, A. K. O. (2014). Amazônia em favor de uma nova agricultura na Amazônia. Revista Terceira Margem, 1(5), 19-34.

Instituto Brasileiro de Geografia e Estatística (2017). Brasil, Ceará, Beberibe.

Instituto Americano de Culinária (2011). Chef Profissional (4a ed.). Senac.

Kolosz, B.W., Athanasiadis, I. N., Cadisch, G., Dawson, T. P., Giupponi, C., Honzák, M., Martinez-Lopez, J., Marvugliaj, A., Mojtahed, V., Ogutu, K. B. Z., van Delden, H., Villai, F. \& Balbi, S. (2018). Conceptual advancement of socio-ecological modelling of ecosystem services for re-evaluating Brownfield land. Ecosystem Services, 33(A), 29-39.

Macedo, A. G. S. R. (2015). As comunidades tradicionais e o último desenvolvimentismo. Revista de Direito e Sustentabilidade, 1(1), 179-195.

Nascimento, G. C. C. (2013). Mestre dos mares: o saber do território, o território do saber na pesca artesanal. In F. A. Cananéa (Org.), Sentidos de leitura: sociedade e educação (pp. 57-68). Imprell.

Pereira, B. E. \& Diegues, A. C. (2010). Conhecimento de populações tradicionais como possibilidade de conservação da natureza: uma reflexão sobre a perspectiva da etnoconservação. Desenvolvimento e Meio Ambiente, 22, 37-50.

Pinto, M. D. N. (2002). Mandioca e farinha: subsistência e tradição cultural. Anais do Seminário Alimentação e Cultura. Ministério da Cultura.

Piperno, D. R. (2011). The origins of plant cultivation and domestication in the New World Tropics: patterns, process, and new developments. Current Anthropology, 52(4), 453-470.

Pinto, M. G. N., Rossato, V. P. \& Coronel, D. A. (2018). Agricultural environmental degradation in Latin America: an index approach in countries of this region. Interciencia, 43(2), 125-131.

Popper, K. (2013). A lógica da pesquisa científica. Cultrix.

Rojas, R. V., Achouri, M., Maroulis, J. \& Caon, L. (2016). Healthy soils: a prerequisite for sustainable food security. Environmental Earth Sciences, 75(3).

Severino, A. J. (2013). Metodologia do trabalho científico (23a ed). Cortez.

Siviero, A. \& Haverroth, M. (2013). Caracterização de etnovariedades de mandioca (Manihot esculenta Crants) da terra indígena Kaxinawa de Nova Olinda, Feijó, Acre, Brasil. Anais do XV Congresso Brasileiro de Mandioca. SBM.

Stefanello, J., Bachi, L. M. A., Gavassoni, W. L. \& Hirata, L. M. (2012). Incidência de fungos em grãos de milho em função de diferentes épocas de aplicação foliar de fungicida Pontim. Pesquisa Agropecuária Tropical, 42(4), 476-481.

Tomich, R. G. P., Salis, S. M., Feiden, A., Curado, F. F.; Santos, G. G. \& Tomich, T. R. (2008). Etnovariedades de Mandioca (Manihot esculentaCrantz) Cultivadas em Assentamentos Rurais de Corumbá, MS. Embrapa. 